\title{
WAT IS VAN CALIFORNISCHE PAP VOOR ONZE OOFTTEELT EN ANDERE CULTUREN TE VERWACHTEN?
}

\author{
(ieschiedenis; a anleiding tot het schrijven \\ vandit artikel.
}

Veel ouder dan de Bordeauxsche pap, die in het jaar 1885 het eerst als bestrijdingsmiddel tegen plantenziekten werd aanbevolen, is een ander bestrijdingsmiddel n.l. een door samenkoken van zwavel en kalkmelk verkregen vloeistof. In Engeland werd reeds in het jaar 1821 een mengsel van zwavel en zeepsop tegen den meeldauw van de perzik aanbevolen; in Amerika gebruikte men in 1833 een met heet water aangeroerd mengsel van $z$ wavel en kalk tegen den meeldauw van den wijnstok, terwijl de roodbruine vloeistof, die men verkrijgt door een mengsel van zwavel en kalk met water te koken, in het midden der negentiende ecuw in Engeland en korten tijd later onafhankelijk daarvan in Frankrijk als middel tegen meeldauwziekten werd uitgevonden. In laatstgenoemd land werd zij naar haren uitvinder "eau Grison" genoemd '). Ook in Amerika kwam zij korten tijd later als middel tegen den meeldauw van den wijnstok in gebruik.

Ofschoon zij in de Europeesche literatuur van de iweede helft van de 19 de eeuw af en toe aanbevolen wordt - tegen meeldauw van den wijnstok, roest der dennenaalden, schurftziekte der peren, rondknop van zwartz bes ${ }^{2}$ ) - is haar

1) De cijfers verwijzen naar aan het slot van dit artikel opgenomen aanteekeningen. 
gebruik, in tegenstelling met dat van poedervormige zwavel, weinig algemeen geworden, hetgeen ongetwijfeld daarmede in verband staat, dat men er toen nog geen geschikte sproeimachines voor kende, terwijl, wat de kascultuur van druiven betreft, een ander bezwaar, de bezoedeling der glasruiten, mede gewicht in de schaal moet hebben gelegd.

Onafhankelijk van haar gebruik in Europa, werd een dergelijke vloeistof in Californië in de ooftteelt ingevoerd in het jaar $1886^{3}$ ). Als middel om schapen te wasschen kende men daar reeds een "lime-sulphur-salt wash", en toen de teelt van schapen meer en meer plaats maakte voor de oofteelt, werd ook hiervoor dit middel bruikbaar bevonden. Direct na de eerste proeven bleek het een goed middel te zijn tegen de San José schildluis, die, van elders ingevoerd, jaren lang de schrik der oofttelers in Amerika was. Van uit Californië heeft haar gebruik tegen schildluizen zich over geheel Noord-Amerika verbreid, ofschoon zij in de Oostelijke Staten - om later te vermelden redenen - een ernstige concurrent in de petroleumemulsies had.

Maar ook in Canada waren reeds sedert het jaar 1884 proeven met "boiled lime and sulphur" genomen tegen de schurftziekte der appelen, ofschoon het nog maar weinig jaren geieden is, dat men het praeparaat, dat intusschen veelal "California wash" genoemd werd, op grooter schaal voor besproeing in den zomer ter bestrijding van verschillende door schimmels veroorzaakte ziekten is gaan gebruiken. Bordeauxsche pap n.l. moet in Amerika de jonge vruchten van gevoelige appelsoorten eenigszins beschadigen; Californische pap heeft deze schadelijke nevenwerking niet. Ook verdraagt het perzikblad geen Bordeauxsche pap, wel daarentegen zeer verdunde Californische pap, terwijl men in de z.g. "self boiled lime-sulphur wash", een pap, waarin de zwavel en kalk voor een grooter deel in vrijen, dan in gebonden vorm voorkomen - ik kom daarop aanstonds terug een middel heeft leeren kennen, dat ook in eenigszins sterker concentraties onschadelijk voor het perzikblad is. 
Sinds eenigen tijd is het hier te behandelen onderwerp, de waarde van Californische pap als bestrijdingsmiddel tegen plantenziekten actueel geworden. Men kan geen buitenlandsch tuinbouwblad opnemen of men leest over "Schwefelkalkbrühe", "bouillie sulfo-calcique", of hoe men het praeparaat verder moge noemen. Ook de Nederlandsche bladen gaan meedoen; er worden vlugblaadjes over zwavelkalk verspreid, in onze taal geschreven, en in enkele der nieuwste prijscouranten van handelaars in tuinbouwartikelen vindt men er prijsopgave van. Het is dus geen wonder, dat tot het Instituut voor Phytopathologie te Wageningen reeds door verschillende practici de vraag gericht werd: wat nu eigenlijk de Californische pap voor onze ooftteelt en andere culturen waard is.

De tijd ligt nog niet zoover achter ons, dat er een overdreven reclame gemaakt werd voor een ander middel: carbolineum. Er werden eigenschappen aan toegekend, die het absoluut niet bezat en menigeen liet zich verleiden tot de meening, dat er een algeheele verjonging zou plats hebben van de weefsels der ermede ingesmeerde boomen. Hoeveel schade er door het daaruit voortvloeiend overdreven gebruik van carbolineum is geleden "), is niet bij benadering aan te geven, maar dit is wel zeker, clat er nog altijd personen zijn, in wier oogen al wat naar carbolineum zweemt, uit den booze is, terwijl men toch bij een verstandig gebruik van carbolineum in de ooftteelt heel wat insektenscliade kan voorkomen.

Wij verkeeren ten opzichte van Californische pap in gunstiger omstandigheden dan destijds ten opzichte van carbolineum. Want er is in Amerika zeer veel mede geëxperimenteerd - wat met carbolineum niet het geval was. In de laatste jaren is men in Europa begonnen proeven ermede te nemen. Ook aan het Instituut voor Phytopathologie te Wageningen zijn wij daarmede bezig. Om zelf niet in den blinde te werken en leiding te kunnen geven aan degenen, die in ons land proeven met Californische pap willen doen, diende eerst een 
literatuurstudie te worden gemaakt, waarvan de resultaten in de volgende bladzijden zijn neergelegd.

Er moet echter uitdrukkelijk op worden gewezen, dat de ervaringen, die men ten onzent zal opdoen, eenigszins kunnen afwijken van de buitenlandsche, wegens verschil in klimaat en in aangeplante ooftsoorten. Daarom zal men in 't algemeen goed doen voorloopig de Californische pap slechts op enkele boomen of struiken in vergelijking met andere middelen te probeeren.

Het Instituut voor Phytopathologie ontvangt gaarne mededeeling van de resultaten der in ons land gedane proeven om ze met de resultaten van eigen proeven te kunnen vergelijken en aldus te komen tot een overzicht van de waarde van Californische pap voor onze ooftteelt, dat op eigen ondervinding berust en dat dus uit den aard der zaak juister moet zijn, dan dat, hetwelk wij nu kunnen geven.

\section{Bereiding en eigenschappen.}

Om een inzicht in de werking van „zwavelkalkpap” te verkrijgen, dient men zich van hare bereidingswijze op de hoogte te stellen. $\mathrm{Zij}$ wordt gemaakt door zwavel, kalk en water met elkaar te mengen; tengevolge van de warmte-ontwikkeling, die bij het blusschen der kalk optreedt, heeft een begin van chemische binding van zwavel en kalk plaats.

De dan verkregen massa kan men tot twee verschillende praeparaten verwerken.

Door na den afloop van de warmteontwikkeling de brijachtige massa met koud water te verdunnen, krijgt men een geelachtige, troebele vloeistof, in welke slechts weinig kalk en zwavel chemisch gebonden zijn; deze vloeistof, die voor het gebruik gezeefd moet worden en die, wegens afzetting der er in zwevende bestanddeelen tot een vaste koek, niet kan wor- 
den bewaard, is met minder gevaar voor verbranding op de bladeren van de perzik dan de eigenlijke Californische pap te gebruiken. Haar Amerikaanschen naam „self boiled limesulphur" heeft zij te danken aan het feit, dat geen andere warmte, dan die bij de zelfverhitting vrij kwam, bij hare bereiding is gebruikt. In Europa wordt zij ook wel naar haar uitvinder genoemd; men spreekt b.v. in Frankrijk van „bouillie ScotT."

Door, nadat de zelfverhitting heeft plaats gehad, de brijachtige massa met het water, dat tot hare verdunning dient, te koken en aldus een verdere chemische binding en algeheele oplossing te bewerken, krijgt men de eigenlijke "limesulphur" of Californische pap. Nadere bijzonderheden over de bereiding der beide vormen van zwavelkalkpap vindt men in de aanteekeningen ${ }^{5}$ ).

Het is duidelijk, dat de bereiding voor eenvoudige ooftbouwers eenige bezwaren medebrengt; een areometer ${ }^{8}$ ) kan er niet bij worden gemist, de vrijkomende zwavelwaterstof is onwelriekend en bij inademing een weinig verdoovend; zij tast bovendien (rood) koperen, bronzen en zilveren voorwerpen onder zwartkleuring aan. Een energiek practicus zal deze bezwaren evenwel zeer goed kunnen overwinnen. Wat betreft het kooktoestel, men kan daarvoor de ijzeren voederpotten met vuurhaard gebruiken, zooals die bij ons op het platteland vrij algemeen worden aangetroffen. Waar in korten tijd veel Californische pap noodig is, zal men echter één zeer groote of meerdere van die kookpotten moeten gebruiken. Het bereiden in verscheidene honderden liters te gelijk levert nog grooter moeilijkheden op, tenzij men over een stoommachine beschikt; dan kan men het kokingsproces door stoom onderhouden, zooals het in Amerika wordt gedaan (fig. 1, PI. II). Daar het niet raadzaam is de Californische pap in ons land direct in 't groot te gaan gebruiken, kan men haar - ofschoon zij nog zeer hoog in prijs 
is - voorloopig van vertrouwde handelaars betrekken. Het handelsproduct wordt, volgens voorschrift van de "AgrikulturAbteilung der Schwefel-Produzenten" te Hamburg, in een concentratie van $20^{\circ}$ Beaumé afgeleverd. ${ }^{7}$ )

Om de bij het koken verkregen roodbruine, heldere vloeistof, die, in overeenstemming met het handelsproduct, op een concentratie van $20^{\prime \prime} \mathrm{B}$. wordt gebracht, te bewaren, hevelt men haar over in blikken bussen of flesschen, welke geheel gevuld en goed gesloten worden bewaard. Gebruikt men den inhoud van zulk een vat gedeeltelijk, dan dient op de rest een laagje cener niet drogende olie te worden gegoten, want indroging en inwerking van de lucht veroorzaken de afzetting van vaste stof, waardoor niet alleen gevaar ontstaat voor latere verstopping van de verstuivers der sprocimachine, maar waardoor ook de concentratie der pap afneemt.

Veel beter doet men echter niet meer pap te maken, dan men op ten dag der bereiding kan gebruiken, want het product is redds bij geringe verontreiniging met sommige stoffen aan veranderingen blootgesteld, warvan ons de aard nog niet gehed bekend is, en ter voorkoming warvan wij nog geen raal kunnen geven.

Bij de later te noemen verdunningen ga ik van de veronderstelling uit, dat men pap vall $20^{\circ} \mathrm{B}$. in voorrad heeft.

Californische pap bestaat dus voor een zeer belangrijk gedeelte uit zwavel en zwavel is een beprocfd middel tegen meeldauwzwammen. Ook tegen op planten parasiteerende mijten wordt deze stof aanbevolen. Bij de voor bestrijdingsdoeleinden gebruikte zwavel komt het vooral op cen fijne verdeeling aan. $\mathrm{Nu}$ is in het residu, dat na eene besproeiing met Californische pap op de planten achterblijit, zwavel aanwezig in deeltjes, die vele honderden malen kleiner zijn dan die, waaruit de fijnste "solfo ventilato" 8 ) bestaat. Niet alleen hierom, maar nog om 
een andere reden is er kans, dat de in Californische pap aanwezige zwavel beter tot haar recht komt dan poedervormige zwavel: het sproeiresidu hecht zich n. 1. uiterst vast aan de planten; het is tegen heftige en lang aanhoudende regens evenzeer bestand als het sproeiresidu van Bordeauxsche pap ${ }^{9}$. Ook van een oplossing van zwavellever, een middel, dat eveneens tegen meeldauwzwammen is aanbevolen, onderscheidt de Californische pap zich gunstig. Dit laatste middel, uit zwavel en kali bereid, is, na te zijn ingedroogd, voor een veel grooter gedeelte oplosbaar dan de ingedroogde zwavelkalk; het werkt direct na de besproeiing vrij neftig, maar is spoedig door de regens weggespoeld.

Terwijl zich in Bordeauxsche pap het werkzaam bestanddeel, koper, in onopgelosten toestand bevindt, zijn in Californische pap de werkzame bestandeelen, zwavel, zwavelverbindingen van kalk en zwavelzuurstofverbindingen van kalk, in opgelosten toestand aanwezig ${ }^{10}$ ). Wanneer de beide praeparaten evenwel op de plantendeelen zijn ingedroogd, bestaat er tusschen de wijze, waarop zij werken, een gronte mate van overeenkomst. Reeds vroeger is in dit tijdschrift ") medegedeeld, dat het koper uit het sproeiresidu van Bordeauxsche pap door geringe hoeveelheden van organische zuren, die door de kiemende schimmelsporen wolden afgescheiden, alsmede door het koolzuur van de lucht, wordt opgelost. Onderzoekingen van WaI.LACE ${ }^{12}$ ) hebben ten opzichte van Californische pap iets dergelijks aan het licht gebracht. Kiemende sporen geven aan het water, waarin zij kiemen, eene stof af, die de oplossing der werkzame bestanddeelen van ingedroogde Californische pap bevordert.

Wat betreft de werking op blad- en schildluizen, zoo schijnt die slechts voor een gedeelte te berusten op de directe gevolgen der aanraking. Hare werking moet voor een ander deel verklaard worden uit het feit, dat het op de plantendeelen aanwezige sproeiresidu de zuigsnuit der dieren aantast, terwijl 
bij de schildluizen bovendien is opgemerkt, dat de schilden door dit residu zoo vast aan de schors worden vastgekleefd, dat de jonge dieren er niet onder uit kunnen komen ${ }^{13}$ ). In Californië, waar men in het voorjaar lange droge perioden heeft, blijft de pap, die vóór het uitloopen der boomen is uitgesproeid, zitten tot in den tijd, dat er weer jonge San José luizen aanwezig zijn; het laat zich dus begrijpen, dat men daar in 't algemeen meer op de zwavelkalk als middel tegen San José schildluis vertrouwen kan, dan in de oostelijke Staten van $\mathrm{N}$. Amerika en Canada, waar het in dien tijd nogal eens regent ${ }^{14}$ ).

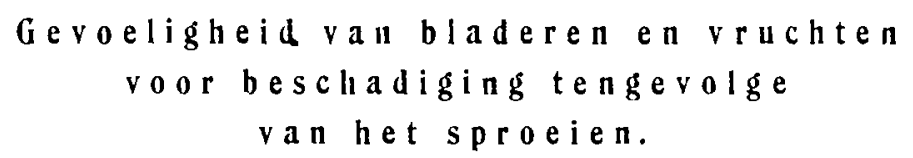

Daar men in den vorm van Californische pap een oplossing op de plantendeelen brengt, waaruit zich onder en na het sproeien vaste stoffen afzetten, is er - afgezien van de mogelijkheid van latere oplossing dier stoffen - direct na het sproeien grooter kans op beschadiging, dan wanneer men met Bordeauxsche pap sproeit, die de werkzame bestanddeelen in onopgelosten vorm bevat. Dus dient men - op straffe van het blad te verbranden - zóó dun te sproeien, dat de fijne droppeltjes niet tot groote droppels samenvloeien en gaan afdruipen. Men moet dus ook niet sproeien als de bladeren nat zijn van den regen.

De jonge, pas uitgeloopen blaadjes kunnen, zooals ook bij onze proeven op appels, peren, kruis- en zwarte bessen bleek, bij voorzichtig sproeien vrij sterke concentraties van Californische pap verdragen, b. v. de standaardvloeistof (van $20^{\circ} \mathrm{B}$.) met haar tienvoudig volumen water verdund $\left.{ }^{*}\right)$, terwijl later de kans op beschadiging, zelfs bij het gebruik van pap, die tweemaal zoo

*) In de tabel is, voorzichtigheidshalve, eene minder sterke concentratie opgegeven. 
verdund is, veel grooter wordt. Dat komt, volgens in Amerika verrichte onderzoekingen, daarvan, dat het pas ontplooide blad meestal nog een geheel gave opperhuid heeft, terwijl na eenigen tijd infectie door schimmels of wel aantasting door bladluizen kan hebben plaats gehad, zoodat door de daarbij ontstane wondjes de bijtende bestanddeelen der pap binnendringen ${ }^{15}$ ). Hetzelfde geldt, zooals door verschillende Amerikaansche onderzoekers is aangetoond, voor beschadiging door Bordeauxsche pap teweeggebracht ${ }^{15}$ ), terwijl ook in ons land na besproeiing met Bordeauxsche pap waarnemingen gedaan zijn, die de juistheid der hier vermelde opvatting bevestigen ${ }^{18}$ ). In Duitschland is er trouwens door experimenteel onderzoek het bewijs voor geleverd ${ }^{17}$ ). In verband hiermede kan ook nog worden meegedeeld, dat bij op armen grond staande, slecht groeiende boomen de meeste beschadiging als gevolg van de besproeiing met een der genoemde bestrijdingsmiddelen wordt waargenomen.

Een der redenen, waarom de Californische pap in Amerika bij de bestrijding van de schurftziekte van appelen een ernstige concurrent is geworden van de Bordeauxsche pap is deze, dat de eerste bij voorzichtig gebruik minder aanleiding geeft tot beschadiging van het blad en de vruchten van daarvoor gevoelige soorten dan de tweede.Op de vruchten verraadt zich deze beschadiging, die het gevolg is van latere oplossing van koper, door de oppervlakkige vorming van kurklijstjes ${ }^{18}$ ). Ook in ons land is de appel eenigszins gevoelig voor Bordeauxsche pap, meer gevoelig dan de peer, zooals ons vooral in zeer vochtige jaren is gebleken; daarom zijn vele fruittelers ervan teruggekomen om de besproeiïng van hun boomen in den zomer te herhalen. Onder den invloed eener vochtige weersgesteldheid blijft de huid der bladeren dun en teer, dus uiterst vatbaar voor infectie en verwonding, zoodat in verband met het bovenstaande te verklaren is, dat de Bordeauxsche pap dan schadelijk werkt. 
Ook de kruisbes en de perzik zijn voor Bordeauxsche pap gevoelig ${ }^{19}$ ). In hun gedrag tegenover zwavelkalk vertoonen de kruisbessen dit eigenaardige, dat de behaarde soorten er minder goed tegen bestand zijn; trouwens reeds bij bepoedering met zwavel laten zij het blad vallen. De onbehaarde soorten verdragen zwavel en zwavelkalk zeer goed ${ }^{20}$ ).

Bij de perzik is het iets anders; deze fruitsoort bezit geen specifieke gevoeligheid voor zwavel. Als men maar voorzichtig sproeit met Californische pap, die met haar 50-voudig volumen water is verdund, dan wordt het perzikblad, volgens Duitsche berichten ${ }^{21}$ ), niet beschadigd. In Amerika, waar men met de iets minder sterk verdunde pap slechte ervaringen heeft opgedaan, is het vraagstuk der besproeiing van bebladerde perzikboumen op andere wijze opgelost: men gebruikt daar n.l. de reeds genoemde "self boiled lime sulphur" ${ }^{23}$ ).

Technische bezwaren bij het sproeien; eischen a an de machines te stellen; bijmenging van vergiften; geheiminidelen.

In Amerika sproeit men den boomgaard in den regel met behulp van op wagens bevestigde machines, dic door benzinemotoren gedreven worden; de sproeivloeistof treedt onder zeer hoogen druk uit en kan, al naar de constructie van den verstuiver, die men kiest, met groote kracht, doch iets minder fijn, of wel in uiterst fijne nevels op de planten worden gebracht. De sproeislangen worden gevoerd van af houten torens, die boven het reservoir gebouwd zijn (zie fig. 2, pl. II). In den winter sproeit men krachtig en overvloedig; men rijdt soms vier maal tusschen de boomen door om ze van alle kanten te kunnen raken of herhaalt de tesproeiing na een kort tijdsverloop. In den zomer daarentegen besteedt men er al zijn aandacht aan om dun en gelijkmatig te verstuiven. Van dit voorzichtig sproeien in den zomer gaf ik de voordeelen reeds aan. Het krachtig en 
grover sproeien in den winter heeft een ander voordeel - of liever het dient om, althans eenigszins, een nadeel te voorkomen, dat aan het gebruik van Californische pap verbonden is. Deze vloeistof toch dringt uit zichzelve weinig door in reten en spleten. $Z i j$ hecht zich veel minder goed aan de takken der appelboomen, waar deze bij de knoppen met haren zijn bedekt, dan op die van boomen met glad en kaal hout $Z_{i j}$ hecht zich zelfs bijna in 't geheel niet aan de vettige, met wasdraden bekleede oppervlakte van vele luissoorten en komt met de luizen zelve niet in aanraking. Wanneer men vergelijkende proeven neemt met zwavelkalk en met middelen, die veel zeep en koolwaterstoffen bevatten (emulsies van petroleum of carbolineum b.v.) op luizen, die met witte wasdraden bedekt zijn, dan is het opvallend hoeveel beter de emulsies de luizen bevochtigen ${ }^{23}$ ).

Nog een andere moeilijkheid brengt het gebruik van zwavelkalk mede, die voor vele kleine oofttelers, die zich op het sproeien met Bordeauxsche pap hebben ingericht, zeer zwaar zal wegen: rood koper, het metaal, waaruit bijna alle in ons land in gebruik zijnde pulverisateurs zijn gemaakt, wordt zeer sterk door Californische pap aangetast. Laat men een stuk koperblik in de verdunde pap gedurende eenige uren staan, dan is een zwarte laag van kopersulfide gevormd, die bij droging afbladert. Ook brons wordt aangetast; geel koper zoo goed als niet; evenmin ijzer, zink, tin en lood.

De meest bekende fabrieken van pulverisateurs leveren met het oog hierop tegenwoordig rood koperen machines, die geheel vertind, of ijzeren toestellen, die van binnen verlood zijn; of wel zij maken de machines van een legeering, die tegen de inwerking van het praeparaat bestand is. Hierbij dient te worden opgemerkt, dat tin door Bourgondische pap wordt aangetast; daarom zou ik machines, die van binnen verlood, of van geel koper gemakkt, en dus tegen beide sproeistoffen 
bestand zijn, prefereeren. De grootere sproeipompen, die men op een vat plaatst (barrel-pumps), zijn meestal, voor zooverre zij met de vloeistof in aanraking komen, vervaardigd van geel koper en dus tegen de inwerking van Californische pap bestand $\left.{ }^{*}\right)$. De caoutchoucbuizen worden niet merkbaar door de Californische pap aangetast.

Het verdient natuurlijk aanbeveling de sproeimachines na het gebruik van Californische pap goed schoon te maken, wat trouwens voor het gebruik in 't algemeen geldt.

Voor ik overga tot een nadere bespreking der resultaten, die men in het buitenland met Californische pap heeft verkregen, moge er nog even de aandacht op worden gevestigd, dat het soms wenschelijk is onder dit middel een arsenicumpraeparaat te mengen, om tegelijkertijd tegen vretende insecten te velde te trekken. Het gebruik van geheimmiddelen, die, volgens de reclame, die er voor gemaakt wordt, de werking van zwavelkalk en van arsenicum in zich vereenigen ${ }^{24}$ ), verdient geen aanbeveling. Waarvoor zou men ze ook koopell, wanneer de twee hoofdbestandeelen als praeparaten van constante samenstelling bij vertrouwde handelaars te bekomen zijn ?

Schweinfurter groen is voor het aangegeven doel niet, loodarseniaat wel bruikbaar. De eerstgenoemde stof toch gaat met Californische pap verbindingen aan, welke zeer schadelijk voor groene plantendeelen zijn. Ook bij de toevoeging van loodarseniaat aan zwavelkalk heeft een inwerking plaats ${ }^{25}$ ), maar het bleek, dat de werkzaamheid van de pap daardoor vergroot wordt, zonder dat de arsenicumwerking vermindert en ook zonder dat het gevaar voor groene plantendeelen toeneemt ${ }^{26}$ ).

De hoeveelheid, waarin men in Amerika loodarseniaat ge-

*) Het vraagstuk der inwerking van sproeimiddelen op de metalen der machines, waarmede zij in aanraking komen, zal in een der volgende artikelen van dit tijdschrift uitvoeriger worden behandeld. 
woonlijk toevoegt, bedraagt $1 / 2 \mathrm{KG}$. op $100 \mathrm{~L}$.. Men roert het met een weinig water aan tot geen kluitjes meer aanwezig zijn en mengt dit papje onder de tot de gewenschte verdunning gebrachte Californische pap ${ }^{27}$ ). Men heeft voor het versproeien van zulk een mengsel een pulverisateur met goed werkend roertoestel *) noodig, daar de arsenicum- en loodverbindingen snel bezinken. Bij sproeipompen, die op een ton geplaatst worden, is meestal zulk een roerinrichting aanwezig.

Werkingop de parasieten der ooftboomen.

Om dit artikel kort en overzichtelijk te houden, heb ik al hetgeen uit de literatuur omtrent de werkzaamheid van Californische pap is af te leiden, in een tabel vereenigd, daarbij rekening houdend met de levenswijze der parasieten en met in Nederland opgedane ervaring. Intusschen laat zich in een tabel bezwaarlijk alles zeggen, wat voor een beoordeeling overwogen dient te worden, zoodat ik er nog een en ander ter verduidelijking aan zal toevoegen.

Wat Californische pap als vloeistof voor winterbesproeiïng waard is, komt eerst duidelijk voor den dag, wanneer men een vergelijking maakt met carbolineumemulsie en met Bordeauxsche pap.

Carbolineumemulsie is een uiterst werkzaam hulpmiddel voor den ooftteler, die de goede gewoonte heeft om zijn boomen en struiken in den winter van allerlei ongerechtigheden te zuiveren. ${ }^{* *}$ )

De Bordeauxsche pap wordt door vele oofttelers reeds in den winter toegepast, ofschoon zij tegen de schurftziekte met veel meer succes kan worden gebruikt in den tijd, die onmiddelijk aan den bloei voorafgaat. Ook Californische pap is dan-

* Ook de constructie van sproeimachines, roerinrichtingen e. d. hoop ik nader in dit tijdschrift te behandelen.

**) Over de toepassing van dit praeparaat hoopt de Heer van POETEREN binnenkort nadere gegevens te publiceeren ${ }^{24}$ ). 
de in Amerika genomen proeven leeren het - voor schurftbestrijding meer werkzaam dan in andere tijden ${ }^{4}$ ).

Vandaar dat ik mij in de tabel aan de genoemde tijden voor winter- en voorjaarsbesproeïing heb gehouden.

Wat verder de tweede voorjaarsbesproeïing en de zomerbesproeïingen betreft, of deze moeten worden toegepast en wanneer, hangt af van de hevigheid der schimmelziekte, die men met Bordeauxsche of Californische pap te bestrijden heeft, en van de dierlijke vijanden, die tegelijkertijd door een aan de pap toegevoegd arsenicumpraeparaat kunnen worden vergiftigd. Treedt b. v. in appelboomen, waarop de schurftziekte zeer hevig woedt, in het einde van den bloeitijd wintervlindervreterij op, waarvan men vóór den bloei niets had bespeurd, dan dient, direct nadat de bloemblaadjes zijn afgevallen, een bespuiting met de gecombineerde vloeistof plaats te hebben. Treedt eerst in Juni vreterij van een of andere rupssoort op, of zijn de vruchten in voorgaande jaren steeds aan wormstekigheid onderhevig geweest, zonder dat men daar door andere middelen verbetering in heeft gebracht, dan sproeit men een maand later.

Bij de opgegeven verdunningen beteekent $1+3$ Californische pap van $20^{\circ} \mathrm{B}$, verdund met haar drievoudig volumen aan water, enz. Ofschoon men in Amerika veelal uitgaat van sterkere Californische pap, n.l. $\pm 33^{\circ} \mathrm{B}$., zal ik bij het gebruik maken der daar verkregen resultaten de voor pap van $20^{\circ} \mathrm{B}$. berekende verdunningen opgeven.

$\mathrm{Na}$ wat in het vorig hoofdstuk werd medegedeeld, behoeft het niet te verwonderen, dat men met Californische pap tegen bloedluis (Schizoneura lanigera, HaUSM.) machteloos staat, hoe dikwijls men er ook mede sproeit ${ }^{23}$ ).

Ten aanzien van de vooral in de laatste jaren in ons land zoo buitengewoon schadelijk geworden bladluizen, die meestal in reten en spleten van de schors en oksels der knoppen in 
den vorm van eieren overwinteren, luiden de Amerikaansche en Duitsche berichten meestal - niet altijd - gunstig. Bij de besproeiing met de concentratie $1+2$ en $1+4$ had men in Duitschland alleen als de eieren niet talrijk waren resultaat; niet meer wanneer zij dicht opeen gehoopt waren en elkaar bedekten ${ }^{29}$ ). Van een voorjaarsbesproeiing $1+5$ á 6 , bij het uitloopen der knoppen toegepast en gevolgd door een tweede voorjaarsbesproeiing en twee zomerbesproeiingen van ongeveer $1+20$ was in den staat New-York geen succes tegen bladluizen op appelboomen te bespeuren, terwijl men daar in 't algemeen wel goede resultaten heeft van een winterbesproeiing met de concentratie $1+3$, zooals zij tegen San José schildluis wordt gebruikt ${ }^{30}$ ). Eenmaal uitgekomen bladluizen worden niet door de pap bevochtigd en of het residu der meer verdunde voorjaarsbesproeiingen de jonge groeiende blaadjes voldoende voor de zuigsteken der bladluizen zal beschermen, is zeer te betwijfelen.

Eenigszins langer zal ik bij de schildluizen stilstaan. In Californië is een zeer grondige, desnoods herhaalde winterbesproeiing met ,lime-sulphur" in een concentratie van gemiddeld $1+3^{31}$ ) nog steeds het middel bij uitnemendheid tegen San José schildluis (Aspidiotus perniciosus Comst.). Men mag evenwel uit dit feit niet afleiden, dat ook onze schild-en dopluizen daardoor op even afdoende wijze verdelgd zouden worden.

Onze kommaschildluis (Mytilaspis pomorum Bouché) is tusschen half September en Juni in geen anderen vorm op de takken der ooftboomen aanwezig dan in dien van eieren, welke zich onder het zeer dikke en goed vastgehechte schild bevinden. De San José schildluis daarentegen komt in het klimaat van "the far West" bijna niet tot afsluiting van haar ontwikkelingsgang in den winter en vertoeft in dien tijd meestal als halfvolwassen vrouwelijk dier op de takken en stammen, waardoor zij natuurlijk voor de zwavelkalkpap gevoeliger is. In de 
oostelijke staten van Naord-Amerika en Canada, waar de winterrust dezer soort meer volkomen en het klimaat minder gunstig voor eene duurzame vasthechting der pap is, heeft de zwavelkalkpap in de petroleumemulsies een zwaren concurrent ${ }^{32}$ ). Ofschoon wel degelijk werkzaam, is zij tegen de kommaschildluis aan gene zijde van den Atlantischen Oceaan niet een afdoend middel ${ }^{33}$ ); evenmin is zij dit in de concentratie $1+4$ in Engeland gebleken ${ }^{34}$ ). De goede berichten, welke uit Duitschland over de concentratie $1+2$ tot ons komen ${ }^{35}$ ), worden nader door onze proeven gecontroleerd.

Bestrijdingsproeven op de hier en daar in ons land aangetroffen z.g. pseudo San José schildluis, Aspidiotus ostraeformis CURT., zijn er slechts weinige in Amerika genomen; de resultaten der winterbesproeiing waren minder gunstig dan die, welke op de echte San José scale zijn verkregen ${ }^{36}$ ).

Wat de cultuur van steenooft, bessen en druiven betreft, ofschoon ook op pruimeboomen en aal- en kruisbessen Mytilaspis nog al eens wordt gevonden, heeft men hierbij toch, meer bepaaldelijk op perzik, kruisbessen en wijnstok, te kampen met dopluizen, die in den regel als nog onvolwassen vrouwelijke dieren overwinteren. Bij de kultuur van kasperziken is het vooral Lecanium Corni Bouché, die schadelijk wordt; bij die van kasdruiven is een Pulvinaria-soort niet zonder belang. Ofschoon men tegen de dopluizen, in verband met hun levenswijze, een beter resultaat van Californische pap zou verwachten, heeft winterbesproeiing $1+3$ op Lecanium Corni in pruimeboomgaarden in Californië uitgevoerd, toch lang geen afdoende resultaten gegeven. In den zomer bleek, dat de besproeide boomen slechts weinig minder geïnfecteerd waren dan de niet besproeide ${ }^{37}$ ).

$\mathrm{Nu}$ behoeft deze geringe waarde van Californische pap ter bestrijding van de dopluizen onzer kasperziken en druiven niet zoo heel zwaar te wegen, daar de kassen - als de omstandig- 
heden het toelaten - op zeer afdoende wijze van perzikdopluis met blauwzuurdamp kunnen worden gezuiverd ${ }^{38}$ ), terwijl, wat de druiven betreft, reeds lang bij ons een - zij het dan ook niet gekookt - breiachtig mengsel van zwavel en kalkmelk voor de winterbehandeling in gebruik is.

Ten aanzien van de op verschillende ooftboomen en andere gewassen, vooral in den drogen zomer van het jaar 1911,zoo bijzonder schadelijk geworden mijten (Tetranychus en Bryobia sp.), zijn in Amerika resultaten verkregen, die een groote mate van overeenstemming vertoonen met wat over de schildluizen is medegedeeld. Door een besproeiing met zwavelkalk in het vroege voorjaar worden de wintereieren niet gedood; maar het sproeiresidu is zeer werkzaam tegen de uitkomende jonge dieren ${ }^{39}$ ). Het was trouwens reeds lang bekend, dat mijten zeer gevoelig zijn voor zwavel en zwavelkalk ${ }^{40}$ ).

Ook de galmijten, die de rondknoppen der zwarte bessen teweegbrengen (Phytoptus ribis NAL.) en die zich, als er nieuwe knoppen aan de jonge scheuten gevormd worden, daarheen begeven, kan men, door de struiken in dien tijd onder de zwavel te houden, bestrijden; althans CollingE ${ }^{41}$ ) raadt driemaal zwavelen aan met tusschenpoozen van drie weken, terwijl ook reeds in het jaar 1888 zwavelkalk door miss ORMEROD tegen deze ziekte werd aanbevolen ${ }^{42}$ ). Behalve zwavel en zwavelkalkpap worden door ons nog late winterbesproeiingen met carbolineum-emulsie tegen rondknop beproefd; dit laatste middel toch belooft ook tegen de pokziekte der peren resultaten.

De pokziekte van de peren, die eveneens door in de knoppen overwinterende galmijten (Phytoptus pyri Sor.) wordt veroorzaakt, kan, zooals uit verschillende Amerikaansche berichten blijkt, door een late winterbesproeiing met petroleumemulsie worden bestreden; van carbolineumemulsie laat zich verwachten, dat zij in dit opzicht niet minder werkzaam zal zijn. Intusschen leest men ook van "lime-sulphur wash" zeer goede resultaten tegen deze ziekte ${ }^{43}$ ). 
Tegen sommige schimmelziekten kan zwavelkalkpap met evenveel succes en op dezelfde tijden worden gebruikt als Bordeauxsche pap.

Bij de bestrijding van appel- en pereschurit (Fusicladium $s p$.) heeft men de gunstigste resultaten van deze middelen gezien, wanneer ze worden aangewend als de blaadjes der gemengde knoppen reeds zijn uitgeloopen en de bloemknoppen zich weldra zullen ontplooien. De latere besproeiingen zijn noodig, waar men met hevige infecties te kampen heeft ${ }^{4}$ ).

Wat de Moniliaziekte betreft, men heeft in Amerika op perziken met goeden uitslag "self boiled lime sulphur" in den zomer gebruikt om aantasting der vruchten, waarvan men daar veel last heeft, te voorkomen ${ }^{+5}$ ), terwijl men in Duitschland voor hetzelfde doel Californische pap $1+50$ anbeveelt, omdat het gebruik van het eerstgenoemde, weinig duurzame en dus steeds zelf te bereiden praeparaat in 't algemeen niet verkieslijk is ${ }^{21}$ ). Ofschoon bif onze appelen en ook bij het steenooft aantasting der vruchten wel eens op vrij groote schaal plaats vindt, is de Moniliaziekte hier toch het meest schadelijk - o. a. bij de appelsoort Codlin Keswick en bij morellen - tijdens en kort na den bloei; zij schijnt in sommige gevallen meer secundair op te treden aan door vorst beschadigde twijgen ${ }^{16}$ ). Intusschen is ook met proefnemingen betreffende de bestrijding van deze ziekte met Californische pap een begin gemaakt ${ }^{*}$ ).

Wij zijn genaderd tot de bespreking der meeldauwzwammen, de parasieten, tegen welke de $z$ wavelkalkpap het eerst gebruikt is. De jarenlange ervaring, verkregen bij de bestrijding van het "wit" in de rozen (veroorzaakt door Sphaerotheca pannosa, WALL. die ook de perzik aantast) in het rosarium, dat naast

*) De Heer. WM. Balk Wzn. te Zwaag deelde mij mede, dat de gewone voorjaarsbesproeiing met Bordeauxsche pap wel degelijk tegen de Moniliaziekte van pruimen en kersen werkzaam is. Er zijn dus ook van Californische pap gunstige resultaten te verwachten. 
het Instituut voor Phytopathologie gelegen is, leert ons, dat Bordeauxsche pap, aangewend in Maart als de knoppen gaan uitloopen, hiertegen een uitstekend middel is. Vergelijkende proeven zijn ingesteld om te zien of bij de bestrijding van deze meeldauwzwam op de perzik Californische pap wellicht nog is te verkiezen.

Met dit laatste middel heeft men in Duitschland meer bevredigende resultaten tegen den meeldauw der appelboomen (meestal Podosphaera Oxyacanthae D.C.) gehad, dan met poedervormige zwavel ${ }^{47}$ ).

Dit geeft eenige hoop, dat men ook tegen den Amerikaanschen kruisbessenmeeldauw (Sphaerotheca mors uvae BERK. et CURT.) iets met Californische pap zal vermogen te doen. Want terwij! wij door late najaarsbesproeiingen met Bordeauxsche pap en zwavellever niet konden bewerken, dat de meeldauw ook maar iets later of minder in het volgend seizoen optrad, heeft een Hollandsch kweeker door eene, minstens eenmaal per week herhaalde bepoedering met zwavel in den zomer de uitbreiding der ziekte door zomersporen (oïdiën) vrijwel kunnen tegengaan. De wintervorm der zwam (de perithecien) werden niet door deze bewerking gedood ${ }^{48}$ ). Mochten onze proeven met zwavelkalk, die ter bestrijding van den Amerikaanschen kruisbessenmeeldauw zijn ingesteld een gunstig verloop hebben, toch verlieze men twee dingen niet uit het ong: ten eerste dat wij tot nog toe alleen als betrouwbaar middel hebben leeren kennen het afsnijden en verbranden van alle zieke scheuten, het omspitten van den grond en het plukken en vernietigen der zieke bessen ${ }^{49}$ ); ten tweede, dat de behaarde soorten geen $z$ wavel en zwavelkalk verdragen.

Het wit in de (kas)druiven (Oidium Tuckeri BERK.) zal men wel altijd door het verstuiven van poedervormige zwavel bestrijden, daar dit veel minder dan het besproeien met zwavelkalkpap, bezoedeling der glasruiten tengevolge heeft. Waar, 
behalve meeldauw, ook mijten de bladeren beschadigen, zou het evenwel zeer gewenscht zijn, de sterker werkende Californische pap te beproeven.

Wat de kruiziekte van den perzik (Exoascus deformans BERK.) betreft, ofschoon de zwam, die deze ziekte veroorzaakt, doordringt in de twijgen, schijnt toch dikwijls infectie uit te gaan van de sporen, die tusschen de knopschubben, overwinteren. Dit blijkt daaruit, dat de ziekte in Amerika meestal op bevredigende wijze door winterbesproeiingen met Bordeauxsche of Californische pap wordt bestreden. Ook in Europa heeft men van winterbesproeiing met Californische pap goede resultaten gezien ${ }^{50}$ ), maar deze zouden - zooals zich uit de ervaring der Amerikanen laat afleiden - evengoed geweest zijn, als men Bordeauxsche had gebruikt. Daarbij verlieze men niet uit het oog, dat het mycelium der zwam in de scheuten overwintert, zoodat het afsnijden der aangetaste scheuten noodig is om de bestrijding volkomen te maken.

De hagelschotziekte der perziken (Clasterosporium carpophilum ADERH.) kan men door zomerbesproeiing met Californische pap bestrijden ${ }^{45}$ ). Men moet hier wel zijn toevlucht nemen tot Californische pap - zeer verdund, of wel "s.elf boiled" omdat Bordeauxsche niet door het perzikblad verdragen wordt. Intusschen vestig ik de aandacht op wat professor RITZEMA Bos onlangs over de bestrijding van deze kwaal mededeelde; hij zag n.l. uitstekende resultaten van het afsnoeien der aangetaste twijgen in den winter ${ }^{51}$ ).

Wieren en korstmossen worden door Californische, evenals door Bordeauxsche pap op de stammen en takken gedood ${ }^{52}$ ).

Wat men evenwel in sommige publicaties vindt vermeld omtrent de meer gezonde en donkergroene kleur, die de bladeren tengevolge eener besproeiing met Californische pap aannemen, dit is niets ongewoons; ik heb het ook wel opgemerkt na eene winterbesproeiing met carbolineumemulsies, terwijl ik het in de 
Amerikaansche literatuur ook als gevolg van de besproeiing met petroleumemulsies vindt opgegeven ${ }^{52}$ ). Het verschijnsel moet waarschijnlijk daaraan worden toegeschreven, dat de geheele gezondheidstoestand van den boom beter wordt na een krachtige bestrijding der parasieten. Dat intusschen ook nog een directe physiologische werking van de Californische pap in 't spel zou zijn, zooals de Bordeauxsche pap op de ermede besproeide bladeren uitoefent, is niet onmogelijk. Deze quaestie zal op den duur wel door experimenteel onderzoek worden uitgemaakt.

Alvorens van de beteekenis der Californische pap ter bestrijding van ooftboomvijanden af te stappen, dien ik er nog de aandacht op te vestigen, dat door prof. DR. ECKSTEIN van de "Forstakademie" te Eberswalde ${ }^{53}$ ) wordt aanbevolen de vloeistof in vrij geconcentreerden vorm te strijken op de schors van boomen, die door wild worden beschadigd: dit zou door de vrij komende zwavelwaterstof de dieren afschrikken. Hij voegt er echter aan toe, dat de dieren langzamerhand eenigszins aan de onaangename lucht gewend raken, en dat het daarom goed is om eenige afwisseling aan te brengen in de voor dit doel toe te passen middelen. Ook wordt wel beweerd, dat de besproeiing met zwavelkalk de knoppen beschermt tegen beschadiging door vogels ${ }^{54}$ ).

In den landbouw schijnt de Californische pap voorloopig weinig toekomst te hebben. De aardappelziekte (Phytophtora infestans de By.), die zoo goed als geheel met Bordeauxsche (of Bourgondische) pap kan worden onderdrukt, bleek op driemaal met Californische pap besproeide planten hevig voort te woekeren ${ }^{55}$ ).

\section{Andere cultures.}

Daar verschillende boomkweekerij-gewassen door dezelfde parasieten worden aangetast, die ook voor ooftboomen scha- 
delijk zijn of door vijanden, die in vorm en levenswijze op ooftboomparasieten gelijken, kan $\mathrm{ik}$, om niet in herhalingen te treden, daarvoor naar de voorafgaande bladzijden verwijzen. Slechts enkele opmerkingen mogen hier nog een plaats vinden.

Dr. J. B. Smith, de onlangs overleden staatsentomoloog van New Jersey, deelde mij bij gelegenheid van een bezoek, dat ik met hem aan de kweekerijen van Boskoop en Oudenbosch bracht, mede, dat de kleur der z.g. "blauwe sparren” niet tegen een besproeing met zwavelkalkpap bestand is. Ook bij toepassing van andere caustische middelen wordt het waslaagje, waaraan deze planten hun kleur te danken hebben, aangetast.

Of het waar is, dat men met Californische pap de roest der sparrenaalden (Chrysomyxa abietis UNG.) kan bestrijden, zal nader doorproeven moeten worden bewezen ${ }^{2}$ ).

Wat de meeldauw der eiken betreft, wanneer men de omgeving der kweekerijen van eiken vrij houdt, of ze er uitroeit, zou men tegen deze ziekte in de Californische pap vermoedelijk een goed bestrijdingsmiddel vinden. Althans prof. Dr. Neger, directeur van de "Forstakademie" te Tharandt, heeft er zeer gunstige resultaten mede verkregen ${ }^{56}$ ), welke door latere proefnemingen van verschillende "Forstmeister" zijn bevestigd. Haar ook op het eikenhakhout te sproeien, is, daar deze cuituur in den regel slecht om de zeven jaar een opbrengst van enkele honderden guldens per $H$. A. geeft, natuurlijk niet loonend.

Wat de rozencultuur betreft, hiervoor zal men wellicht met succes van Californische pap gebruik kunnen maken. Van een vroege voorjaarsbesproeiing met de vrij geconcentreerde pap $1+3$, direct na den snoei (en bij de soorten, die niet worden gesnoeid, iets vroeger) toegepast, kan verwacht worden, dat zij werkzaam is tegen de als ei op de twijgen overwinterde bladluizen en tegen "het wit". Bovendien kan, volgens berichten uit Duitschland ${ }^{57}$ ), rozenroest (Phragmidium subcorticum WiNT.) er door worden tegengegaan - hetgeen m. i. nog ge- 
controleerd moet worden. Een combinatie van Californische pap met loodarseniaat zou, als ook meeldauw aanwezig is, tegen de uitwendig vretende bastaardrupsen, van welke de rozen soms buitengewoon veel te lijden hebben, beproefd kunnen worden.

Nog dient te worden vermeld, dat de Duitsche onderzoeker Martin Schwarz de Californische pap aanbeveelt tegen de aaltjes van het geslacht Aphelenchus, welke verschillende in kassen gekweekte sierplanten, als varens en chrysanthen, aantasten. De planten, moeten, nadat alle doode en verkleurde gedeelten zijn verwijderd, eerst een uur lang onder water worden gehouden om de aaltjes naar buiten te doen treden; vervolgens besproeit men ze met Californische pap $1+40$. De behandeling moet op eenige achtereenvolgende dagen worden herhaald. ${ }^{58}$ )

Er zijn ongetwijfeld nog leemten aan te wijzen in de voorafgaande opsomming der toepassingen van zwavelkalkpap, maar daarbij dient in aanmerking te worden genomen, dat het in den tegenwoordigen tijd ell bij den tegenwoordigen toestand der wetenschap hoogst moeilijk, ja onmogelijk is over eenig omvangrijk onderwerp een werkelijk volledig literatuuroverzicht te geven *). Daar intusschen betreffende de werking van verscheidene der hier behandelde parasieten meerdere berichten werden gevonden, die elkaar bevestigen, meen ik te mogen volstaan met het hier meegedeelde, totdat uit den uitslag van in ons eigen land genomen proeven kan worden beoordeeld in hoeverre de elders verkregen resultaten hier gelden en in hoeverre het middel ook bruikbaar is voor andere, hier niet genoemde ziekten, welke meer bepaaldelijk voor ons van belang zijn.

*) $\mathrm{Bij}$ het verzamelen der literatuur heb ik de hulp gehad van de Agrikultur-Abteilung der Schwefelproduzenten te Hamburg en van den Heer T. SCHOEVERS, waarvoor ik hier gaarne een woord van dank uitspreek. Ook bij de proeven verleent de Heer ScHOEvers krachtige medewerking. 


\section{Voorloopig antwoord op de gestelde vraag.}

De meeste personen, die zich om inlichtingen over de werking van Californische pap tot het Instituut voor Phytopathologie hebben gewend, meenden uit de berichten, die zij er over hadden gelezen, te mogen afleiden, dat men door één besproeiing met dit middel zoowel schadelijke insekten als schimmels zou kunnen bestrijden. Dit is echter, in 't algemeen gesproken, meer, dan men van eenig bestrijdingsmiddel, Californische pap niet uitgezonderd, zal mogen verwachten.

$\mathrm{Na}$ het voorafgaande hoofdstuk, waarvan de inhoud in de hierachter volgende tabel overzichtelijk is samengesteld, kan ik volstaan met te zeggen, dat in vele gevallen, inzonderheid bij appelboomen, de carbolineumemulsie voor winterbesproeiing niet zal kunnen worden gemist, maar dat men in bepaalde gevallen een winterbesproeiing met zwavelkalkpap met voordeel zal kunnen toepassen; de werking van dit laatste middel zal echter altijd eenigszins afhankelijk blijken van de weersgesteldheid, met dien verstande, dat men er minder op zal kunnen vertrouwen naarmate het sproeiresidu meer door den regen wordt weggespoeld.

Wat de latere besproeiingen betreft, zal in vele gevallen de werkzaamheid van de Californische pap niet bij die van de Bordeauxsche achterstaan. Bovendien kan men er zonder vrees voor beschadiging appel- en perzikboomen mede besproeien, terwijl het in de verdunningen, die voor deze besproeiingen noodig zijn - althans bij zelfbereiding - zeer goedkoop is.

Daar staat natuurlijk de groote moeilijkheid tegenover, dat er in ons land heel wat geld is vastgelegd in sproeimachines van rood koper, en dat men zich voor Californische pap nieuwe machines zal moeten aanschaffen. In den eersten tijd zal men dus goed doen zich te houden aan Bordeauxsche pap. Wanneer men evenwel denkt over het aanschaffen van nieuwe machines, dan is het verstandig er zulke te kiezen, die ook tegen Californische pap bestand zijn. 


\section{A A N TEEKENINGEN.}

1) De meeste historische gegevens over zwavelkalkpap en andere sproeimiddelen vindt men in LODEMAN "The Spraying of Plants" (New York 1910; zie b.v. blz. 10, 12, 16, 88 en 158); zie ook Sorauer „Handbuch der Pflanzenkrankheiten” eerste druk (Berlin 1874) blz. 332, waar een oud voorschrift voor zwavelkalk wordt gegeven, zeer veel gelijkende op onze tegenwoordige voorschriften. Het werd toen nog met een kwast op de wijnstokbladeren en de druiven gesprenkeld.

2) Zie ook HollRung „Handbuch der chemischen Mittel gegen Pflanzenkrankheiten" (Berlin 1898) blz. 55 en 56.

3) Zie "Yearbook of the United States Departement of Agriculture 1906", Washington 1907, blz. 429.

4) Hiervoor kan verwezen worden naar het artikel van prof. Ritzema Bos over "Het gebruik van carbolineum in den tuinbouw", jaargang 1908 van dit tijdschrift.

5) Stel, dat men een kookpot heeft van $50 \mathrm{~L}$., dan giet men er 34 L. water in, en streept op een meetstok aan hoe hoog dit staat. Dit water wordt aan de kook gebracht. Onderwijl mengt men 5 kilo bloem van zwavel met eenige liters koud water tot een brei aan en roert hieronder 3 kilo ongebluschte kalk. Bij de blussching der kalk zou de massa droog worden, wanneer men dit niet voorkwam door er meer water onder te roeren. Om het zelfverhittingsproces niet te storen, neemt men hiervoor water uit den kookpot. Terwijl men aldus het mengsel van $z$ wavel, kalk en water op een breiachtige consistentie houdt, neemt dit allengs een donkerder gele kleur aan. Zoodra de warmteontwikkeling is afgeloopen, voegt men de heete brei bij het inmiddels tot koking gebrachte water, kookt nog drie kwartier door onder toevoeging van kleine hoeveelheden water, waarbij men zorgt, dat het gezamenlijk volumen der vloeistof weer op 34 Liter komt. Deze wijze van bereiding is ons aan het Instituut voor Phytopathologie zeer goed bevallen. 
De verhouding voor "self boiled" is 2 deelen kalk, 2 deelen zwavel en 100 deelen water. De verkregen troebele vloeistof moet door een zeef in het reservoir der sproeimachines worden gegoten en direct verbruikt, daar zich anders de onopgeloste bestanddeelen afzetten.

6) Areometers voor vloeistoffen met een S. G. van 1 tot 1.2 , tevens voorzien van een schaal volgens Beaumé $(20 \mathrm{~B}$. komt ongeveer overeen met het S. G. 1.16), zijn bij instrumenthandelaars reeds in den prijs van $f 1$. - verkrijgbaar.

Dr. van Gulik, leeraar in de natuur- en weerkunde aan de Rijks Hoogere Land-, Tuin- en Boschbouwschool, heeft, op ons verzoek, welwillend gecontroleerd, dat de cijfers achter de decimaal van het S. G. geplaatst, evenredig aan de concentratie afnemen. Verdunt men dus de standaardvloeistof (S. G. 1.16) tot de halve sterkte dan is het S. G. 1.08, verdunt men haar wederom tot de halve sterkte dan is het $1.04 \mathrm{enz}$. Men kan dus door het S. G. eener verdunde pap te bepalen, een inzicht krijgen in den graad der verdunning.

Men heeft echter voor het bepalen der S. G., die weinig van 1 verschillen, veel gevoeliger areometers noodig, dan de bovengenoemde, en doet daarom goed het S. G. te controleeren vóór de verdunning heeft plaats gehad.

7) In Duitschland kost het in vaten van 200 kilo $14 \mathrm{Pf}$ per K., in vaten van $60 \mathrm{~K}$. $16 \mathrm{Pf}$. per K., in bussen van 30 K. $19 \mathrm{Pf}$. per Kilo. Bij ons is het tegenwoordig nog ongeveer twee maal zoo duur.

8) Dit fijnste merk van poedervormige zwavel is uit gemalen en gezeefde zwavel afgescheiden, door er een luchtstroom over te voeren. Verdunt men Californische pap met veel water, dan scheidt er zich colloïdale zwavel uit af, die zoo fijn is, dat zij met de vloeistof door filtreerpapier loopt.

9) Van de vele middelen, die PICKERING beproefde om kalk beter aan de boomen te doen hechten, bleken geringe hoeveel- 
heden zwavelkalk een van de meest werkzame te zijn (8th Report of the Woburn experimental Fruit Farm, London 1908), verder kan ik hieromtrent verwijzen naar E. S. SALmON, F. L. S. „A lime sulphur wash for use on foliage", Journal of the Board of Agriculture and Fisheries, London, XVII, No. 3 (Iuni 1910); naar A. STEFFEN, in "der praktische Ratgeber im Obstund Gartenbau", 1911 blz. 13; en naar onze eigen ervaring.

10) In hoofdzaak ontstaan daarbij de oplosbare polysulfiden $\mathrm{Ca} \mathrm{S}_{4}$ en $\mathrm{Ca} \mathrm{S}_{5}$, terwijl aanvankelijk zich vormend calciumthiosulfaat $\left(\mathrm{Ca} \mathrm{S}_{2} \mathrm{O}_{3}\right)$ bij koken in calciumsulfiet $\left(\mathrm{Ca} \mathrm{SO}_{3}\right)$ en zwavel overgaat. Zie van Sujke, Hedges en Bosworth. Experiment Station, Geneva, N. Y. Bull. 319 (1909) en ook Haywood, Journ. of the Amer. Chem. Soc. 27, 3, 224.

11) W. Ruhl.and „Zur Kenntnis der Wirkung des unlöslichen basischen Kupfers auf Pflanzen, mit Rücksicht auf die sogenannte Bordeauxbrühe", Arb. a. d. Biol. Abt. f. Land- und Forstwissensch. am Kais. Gesundheitsambte, 1905, blz. 157.

12) E. Wallace, F. M. Blodgett, en L. R. Hesler "Studies of the fungicidal value of lime-sulfur preparations", Cornell University, Departement of Plant Pathology, bull.290. Jan. 1911. De gevolgde laboratoriummethode bestaat daarin, dat men kiemproeven inzet met sporen van verschillende schimmels, 0.a. van Fusicladium en Monilia. Dit wordt vergelijkenderwijze gedaan in droppels water, die geplaatst zijn op ingedroogde droppeltjes Cal. pap; in ciroppels water, die in aanraking geweest zijn met ingedroogde Cal. pap en in droppels water, die eerst in aanraking zijn geweest met kiemende sporen en daarna met ingedroogde Cal. pap.

13) Zie o. a. „Woburn experimental Fruit Farm, 6th Report, 1906" blz. 154.

14) Zie het door Prof. Ritzema Bos opgemaakte „Verslag omtrent een onderzoek, ingesteld naar de San José schildluis" in jaargang 1899 van het "Tijdschrift over Plantenziekten”, blz. 81. 
15) E. WaLlaCE, „Spray injury induced by lime-sulfur preparations", Cornell University, Dep. of Plant Pathology, bull. 288.

Ook H. H. Whetzel, plant pathologist aan het New York State College of Agriculture doet in "The Fruit Grower”, St. Joseph, Missouri, van April 1911, blz. 14, mededeelingen uit de Amerikaansche literatuur, waaruit dit blijkt.

16) De Heer A. M. Sprenger, rijkstuinbouwleeraar te Maastricht, deelde mij mede, dat boomgaarden, die met Bordeauxsche pap besproeid waren, beschadiging vertoonden waar schurft en bladluizen er in voorkwamen, terwijl geen beschadiging plaats had, waar deze parasieten, tengevolge van voorafgaande besproeiing, afwezig waren.

17) Zie R. SchandeR, „Ueber die physiologische Wirkung der Kupferkalkbrühe" (blz. 544), Landwirtschaftliche Jahrbücher, Berlin 1904.

18) Zeer talrijk zijn de berichten over deze beschadiging van de vruchten, zie b.v. Clinton en BRITTON, 33th and 34th Report of the Connecticut Agricultural Experiment Station (19091910), blz. 584 en WALLACE „Lime sulfur as a summer spray” Cornell Universitv, Dep. of Plant Pathology, bull. 289 e.a.

19) Zie, wat de gevoeligheid van kruisbessen voor Bordeauxsche pap betreft, het jaarverslag over 1909 van het Instituut voor Phytopathologie. (Mededeelingen van de Rijks Hoogere Land-, Tuin- en Boschbouwschool, Deel V, blz. 72.)

Dat de perzik voor allerlei besproeiingsmiddelen zeer gevoelig is, is een bekend feit; zie 0.a. „Ziekten en Beschadigingen der Ooftboomen" door prof. Dr. J. Ritzema Bos (Groningen 1905), Deel II, blz. 83.

20) De in Holland opgedane ervaring leert, dat de ruige roode en de ruige gele zeer gevoelig voor zwavel zijn; de Engelsche witte in mindere mate (jaarverslag over 1910 van het Instituut voor Phytopathologie, Mededeelingen van de Rijks Hoogere Land-, Tuin- en Boschbouwschool, Deel V, blz. 159 en 160). 
Aan opgaven van L. Peters in „Illustr. land- und hauswirtsch. Beilage zum Wochenblatte Bund der Landwirte" 1911, blz. 45, KLEEMANN in „Handelsblatt für den Deutschen Gartenbau, 1911, blz. 41 en STrubE, in „Provinzialsächsische Monatschrift für Obst-, Wein- und Gartenbau, Sonderabdruck aus no. 11 und 12, 1910, blz. 8, ontleen ik hier, dat Yellow Lion, Leader, Früheste von Neuwied, Rote Eibeere, Rote Preisbeere, Früheste Gelbe, Sämling von Maurer, Drums major, Gelbe Riesenbeere, Langley Gage, Hellgrüne Samtbeere en Grüne Edelbeere voor deze beschadiging vatbaar bleken, terwijl de volgende soorten er niet aan onderhevig waren: Lady Delamere, Shannon, Industry, Jenny Lind, Chatauqua, Hönings Früheste, May Duke, Rote Triumphbeere, Rote Frühe, Companion, Bloodhound, Golden Fleur, Prinz von Oranien, Runde Gelbe, Lovets Triumph, Grüne Riesenbeere, Späte Grüne, Grüne Smaragdbeere, Frühe Dünnschalige, Alicant, Weisse Kristallbeere, Weisse Volltragende, Weisse Triumphbeere en Victoria.

De proeven, welke aan deze opgave ten grondslag liggen, zijn, volgens mededeeling van de Agrikultur-Abteilung der Schwefelproduzenten G. m. b. H. te Hamburg in het jaar 1909 genomen onder leiding van den „Bund deutscher Baumschulenbesitzer, (Geschäftsführer H. WIMmER, Wietzenbruch b/Celle, Prov. Hannover) door verschillende bekende boomkweekers. Op de „Vortragskursus der Obstbauabteilung der Landwirtschaftskammer für die Provinz Brandenburg" bieek er onder de daar aanwezige deskundigen overeenstemming te bestaan over het feit, dat toch ook de Rote Preisbeere tegen zwavelkalkpap, evenals Hönings Früheste, Späte Grüne en Golden Bull, bestand is, en dat de soort Früheste Gelbe reeds eenige uren na de besproeiing het blad laat vallen.

21) KleEmanN en STRube in "Provinzialsächsische Monatsschrift für Obst-, Wein- u Gartenbau", 1911, blz. 191.

22) W. M. ScotT en A. L. QuainTance „Farmers Bulletin 
440, U. S. Department of Agriculture" (Maart 1911).

23) Wat betreft het slecht doordringen in oneffenheden en de beharing van appeltwijgen en knoppen, zie het onder 3 genoemde "Yearbook" blz. 431 en John B. Smith "New Yersey Agric. Exp. Stat. Bull. 213" (Sept. 1908) blz. 16 en 42.

Dat de bloedluis met Californische pap niet bestreden kan worden blijkt duidelijk uit Bull. No. 330 (Dec. 1910) van het "New York Agricultural Experiment Station (Geneva)" door PaRROTT en SCHOENE, blz. 464. Ook bleek ons, dat men de in witte wasdraden verscholen op Abies voorkomende luizen van het geslacht Chermes niet met zwavelkalkpap kan bereiken.

24) In Amerika brengt men praeparaten in den handel, die behalve zwavelkalk nog andere stoffen bevatten b.v. "Sulfocide”, "Bogart's Sulphur Compound", "One for All”; in Engeland "Medela", dat volgens analyse, welwillend door den Heer Aberson, leeraar in scheikunde aan de Rijks Hoogere Land-, Tuin- en Boschbouwschool, voor ons verricht, uit een oplossing van zwavelkalk bleek te bestaan ; in Duitschland ,Kalifornit" e.a.

25) Zoowel de kalk als de zwavel gaan met arsenicum een onoplosbare verbinding aan, van welke de laatste gedeeltelijk weer in oplossing gaat. Bovendien slaat er zwart loodsulfide neer.

26) Zie o.a. de onder 16 genoemde publicatie van WALLACE.

27) De bereiding van een loodarseniaat houdend sproeimiddel door bijeen te mengen een oplossing van azijnzuur lood en een oplossing van arseenzure natron is, waar men er voldoende zorg aan kan besteden, zeer aan te bevelen wegens de fijnheid van het neerslag, dat dan ontstaat. Men heeft voor 100 Liter sproeivloeistof noodig 480 gram azijnzuur lood, 180 gram arseenzure natron en $11 / 2 \mathrm{KG}$. gebluschte kalk. De oplossingen moeten in verdunden toestand bij elkaar worden gemengd. Wil men Californische pap ermede combineeren, dan verdunt men deze met een gedeelte van het water en voegt er dan het mengsel der genoemde oplossingen aan toe. 
Zie voor de uitstekende resultaten, die het Instituut voor Phytopathologie verkreeg bij de bestrijding van den wintervlinder, het jaarverslag over 1909 in Mededeelingen der R. H. L. T. en B. S., Deel V (blz. 117.) De werkzaamheid tegen de rupsjes der wormstekige appelen is door verschillende Amerikaansche en Duitsche proefnemers bewezen, zie u.a. "Cultura" 1908, blz. 550.

28) Ook in de onder 4 genoemde verhandeling en in de laatste jaarverslagen van het instituut voor Phytopathologie (vanaf 1907 in de Mededeelingen der Rijks Hoogere Land-, Tuin- en Boschbouwschool) vindt men hierover verschillende gegevens.

29) Zie het bericht van O. MARQUARDT in het boven onder 21 genoemde tijdschrift, dezelfde jaargang, dezelfde blz.

30) Zie over het negatief resultaat der slappere oplossingen het onder 23 genoemde bulletin van Geneva; over de werkzaamheid der sterkere oplossingen: QUAINTANCE, blz. 446 van het onder 3 genoemde "Yearbook".

31) Zie behalve het onder 3 genoemde "Yearbook" blz. 446 , b.v. J. L. PHILliPs „Lime-sulphur wash" in „Virginia State Crop Pest commission", Circ. 1, new series (1906).

32) Zie 0.a. Howard in "Yearbook of the U. S. Dep. of Agric. for 1894" blz. 275 ; het onder 14 genoemde verslag van prof. Ritzema Bos; Marlate "Important insecticides" U.S. Dep. of Agr., Farmers Bull. No. 127, blz. 27 ; verder ParRotT, HodGKISS and SCHOENE in "New York Experiment station Geneva Bull. 302" (April 1908).

33) QuainTance and SAsscer "The oyster-shell skale and the scurfy scale", U. S. Departement of Agriculture, Bur. of Entomology, Circ. No. 121.

34) Eight Report of the Woburn Experimental Fruit Farm (London 1908; blz. 47 en 52. Aan de zwavelkalk, die Pickering bij de hier beschreven proeven gebruikte, was wat soda toe- 
gevoegd. Er werden slechts $20 \mathrm{pCt}$. van de eieren gedood. Hij kon de werkzaamheid belangrijk vergrooten door er petroleumdestillaten aan toe te voegen; als hij dan de zwavelkalk wegliet en alleen petroleumdestillaten gebruikte, kreeg hij even goede uitkomsten. Wij hebben in onze carbolineumemulsie een nog werkzamer middel.

35) Zie O.MARQUARDT in "Sonderabdruck aus Nr. 11 und 12, Jahrg 1910 der Provinzialsächsichen Monatsschrift für ObstWein und Gartenbau der Landwirtschaftskammer für die Provinz Sachsen zu Halle a. S., blz. 1.

36) P. R. JONES "Tests of Sprays against the European fruit Lecanium and the European pear scale" U. S. Dep. of Agric.; Bur. of Entomology, Bull. No. 80, Part VIII. (Nov. 1910) blz. 155.

37) Zie het onder 3 genoemde „Yearbook”, blz. 446, en de onder 36 genoemde rapporten, blz. 151 .

38) Zie "De Perzikdopluis en hare bestrijding" door H. M. QUANJER in "Tijdschrift over Plantenziekten" 1909, blz. 115-126.

39) In ,The Fruit Grower", _St. Joseph, Missouri, Sept. 1910 is op blz. 18 een referaat van Bull. 152 van het Colorado Experiment Station gegeven, waaruit dit blijkt.

40) Zie "Yearbook of the United States Departement of Agriculture for 1895" Washington, blz. 586.

41) W. E. Collinge „First Report on Economic Biology, Birmingham, 1911, blz. 17.

42) Miss ORMEROD „Report of Observations on injurions Insects, 1888, blz. 80 .

43) De werkzaamheid van petroleumemulsies is reeds ter sprake gebracht in jaargang 1906 van het "Tijdschrift over Plantenziekten", blz. 97. PARROTT noemt in Bull. 306 van het New York Agricultural Experiment Station, Geneva, „Control of leaf, blister mite in apple orchards" zoowel petroleum emulsies als zwavelkalk onder de werkzame bestrijdingsmid- 
delen van deze galmijt. Goede resultaten van beide middelen tegen de pokziekte der peren vindt men ook vermeld in de "Reports of the Experimental Farms van Canada" (b.v. dat over 1903; J. FLETCHER was daar toen entomoloog-botanicus). Aanbeveling van zwavelkalkpap tegen deze ziekte vindt men ook in de nieuwere Europeesche literatuur, b. v. van Grosdemange in "Le petit Journal agricole", Paris, 1910, blz. 340.

44) Over Californische pap als middel tegen appelschurft kan men zich uit een zeer groot aantal berichten gegevens verschaffen. Ik noem o.a. PARROTT in de latere bulletins van "New York Agric. Exp. Station" te Geneva, STewart in die van "Pennsylvania State College Agric. Exp. Station", Wallace in die van "Cornell University, Depart. of Plant Pathology", W. M. ScotT "Report of Experiments in Virginia onder Direction of the U. S. Dep. of Agric." (the Fruit Grower, St. Joseph, Missouri, Febr.) 1910, blz. 11 en G. P. Clinton en W. E. Britton in ,33th and 34th Reports of the Connecticut Agricultural Experiment Station (1909 en 1910) blz. 584; verder onder de berichten uit Duitschland: Boll, Hönings e. a. in „Deutsche Obstbauzeitung' 1911, Heft 30, en 1912 Heft 3; onder die uit Frankrijk: MArRe „Le prcgrès agricole et viticole (Montpellier) 1912, No. 1 (blz. 21).

45) SCOTT and QuainTance "Spraying peaches for the Control of Brown-rot, Scab and Curculio," U. S. Dep. of Agric., Farmer's Bulletin 440 (1911).

46) Zie onze jaarverslagen in "Tijdschrift over Plantenziekten” 1907, blz. 48 en "Mededeelingen der Rijks Hoogere Land-, Tuin- en Boschbouwschool", Deel V, biz. 81.

47) Boll, „Deutsche Obstbaizeitung”, 1912, Heft 3.

48) Zie ons jaarverslag in "Mededeelingen der Rijks Hoogere Land-, Tuin- en Boschbouwschool", Deel V, blz. 8.

49) Prof. J. Ritzema Bos en N. vain Poeteren, brochure voer den Amerikaanschen Kruisbessenmeeldauw (naschrift). 
50) De zeer uitvoerige Amerikaansche literatuur over "Peach Leaf Curl" behoef ik hier niet nader aan te geven. Men vindt in handboeken als dat van DugGar ${ }_{n}$ Fungous Diseases of plants" 1910, deze welbekende zaken vermeld; zie ook de onder 44 genoemde Franscine publicatie.

51) „Onze Tuinen” No. van 24 Febr. 1912.

52) Zie o.a. de onder 36 genoemde publicatie.

53) Prof. Dr. Eckstein, „Technik des Forstschutzes gegen Tiere."

54) Gardener's chronicle, Nr. 3606 (19:0), blz. 61 „The sprayingcampaign".

55) Pethybridge, „Third Repord on Potato-diseases,” Dublin, 1912.

56) DR. F. W. Neger. „Die Ueberwinterung und Bekämpfung des Eichenmehltaus", Tharander forstliches Jahrbuch, Band 62, (1911) blz. 1. De rapporten uit de „Forstrevierverwaltungen Colditz en Moritzburg bevestigen de resultaten van Neger.

57) Zie o.a. „Süddeutsche Flora”, Heidelberg, 1912, No. 3, "Illustr. land- und hauswirtsch. Beilage zum Wochenblatte Bund der Landwirte", Berlin 1911, Nr. 6, blz. 46, e. a.

58) M. Schwartz. "Die Aphelenchen der Veilchengallen und der Blattflecken an Farnen und Chrysanthemum". Arbeiten aus der kaiserlichen biologischen Anstalt für Land- und Forstwirtschaft, VIII (1911), blz. 334. 
PlaAt II.

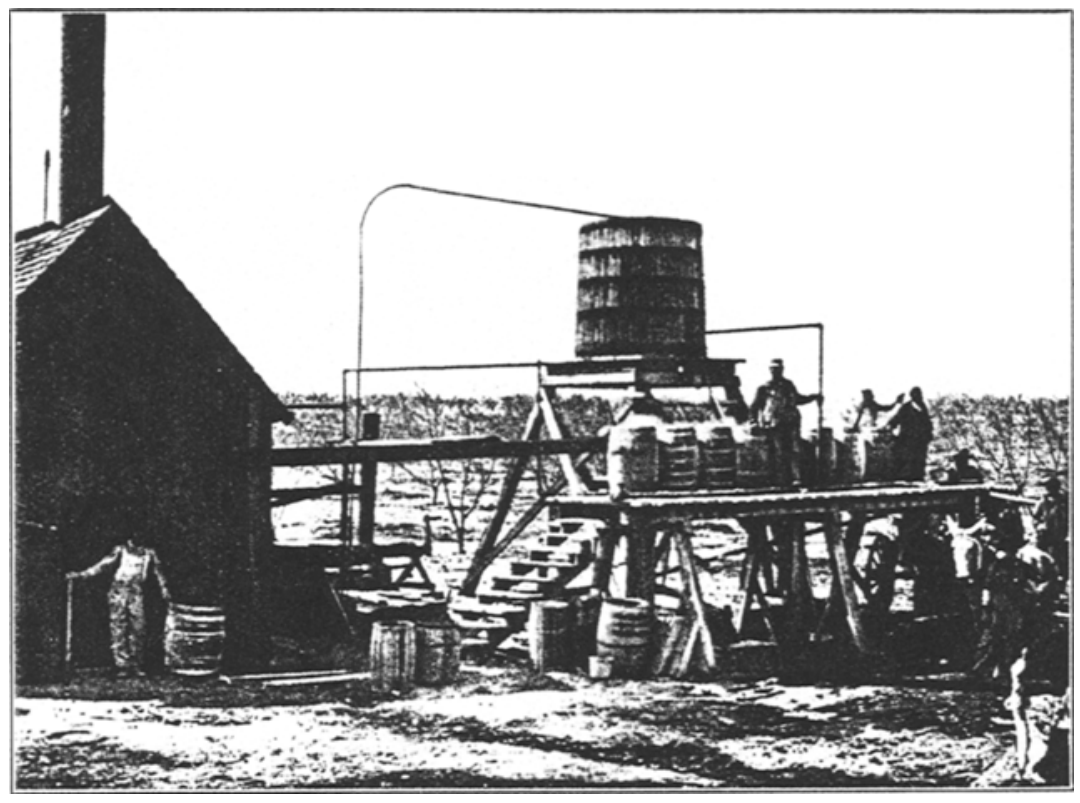

IG. 1. Naar R. I. Smith. (Zie blz. 25.)

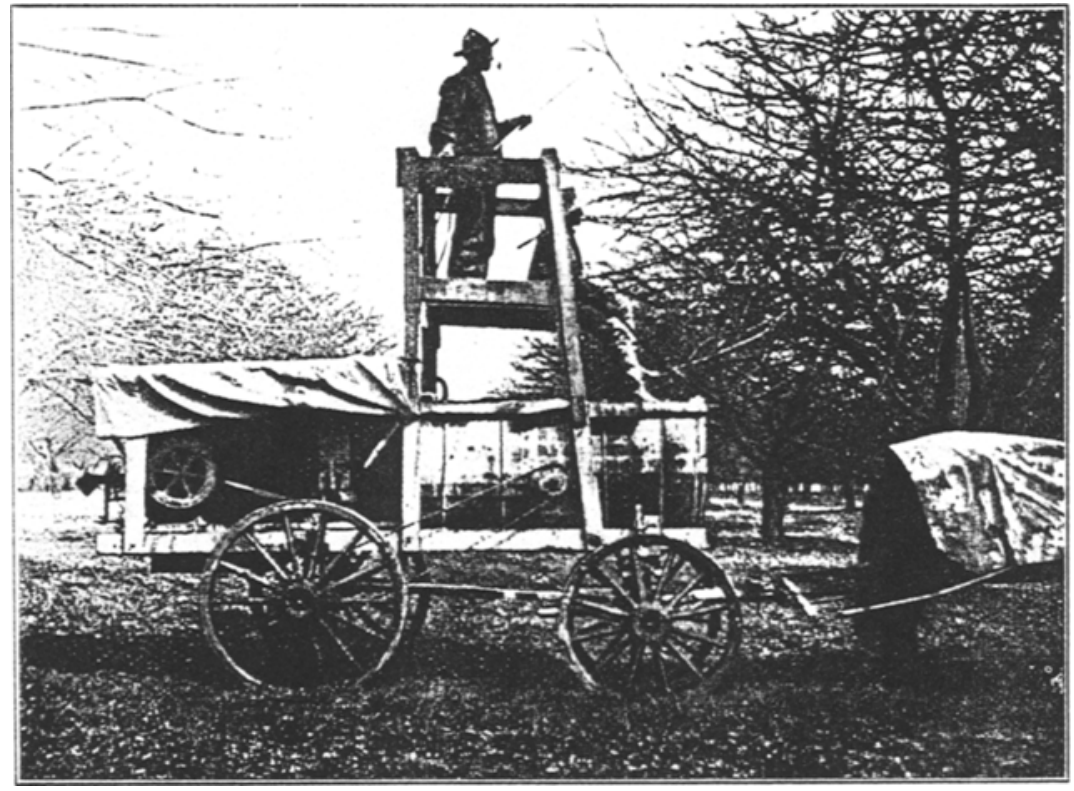

Fig. 2. Naar A. L. Qualstance. (Zie blz. 30.) 